\title{
INGRESSO DE SURDOS ATRAVÉS DAS COTAS NO INSTITUTO DE QUÍMICA DA UNIVERSIDADE FEDERAL DO RIO DE JANEIRO.
}

\author{
ENTRY OF A DEAF STUDENT THROUGH QUOTAS AT THE CHEMISTRY \\ INSTITUTE OF THE FEDERAL UNIVERSITY OF RIO DE JANEIRO.
}

\author{
Cristiana de Barcellos Passinato ${ }^{44}$
}

\begin{abstract}
Resumo
O artigo discutirá possíveis embates ocorridos e soluções geradas para o ingresso e permanência de surdos na Universidade Federal do Rio de Janeiro (UFRJ). Serão confrontadas informações, tais como: alguns números oficiais (PR1/DRE-DIRAC) e situações acerca do discente surdo matriculado em disciplinas no Instituto de Química somente a partir de 2018-1. Este aluno durante o intervalo de 2018 e 2019 permaneceu sob a avaliação e acompanhamento da autora. É importante salientar que foi escolhido o recorte temporal de 2018 e 2019 por se tratar de quando iniciaram as políticas afirmativas por deficiência para pessoas advindas do processo seletivo dos sistemas SiSU e ENEM.
\end{abstract}

Palavras-chave: Surdos. Políticas Afirmativas. Cotas.

\begin{abstract}
The article will discuss possible clashes and solutions generated for the admission and permanence of the deaf at the Federal University of Rio de Janeiro (UFRJ). Information such as: some official numbers (PR1 / DRE-DIRAC) and situations about the Deaf student enrolled in subjects at the Institute of Chemistry will only be compared from 2018-1. This student during the interval between 2018 and 2019 remained under the author's evaluation and monitoring. It is also important to note that the time frame of 2018 and 2019 was chosen because it was when the affirmative policies for disability arising from the selection process of the SiSU and ENEM systems started.
\end{abstract}

Keywords: Deaf. Affirmative Politics. Quotas.

\footnotetext{
${ }^{44}$ Instituto de Química da Universidade Federal do Rio de Janeiro - IQ-UFRJ Secretaria de Estado e Educação do Rio de Janeiro - SEEDUC-RJ acessibilidade@iq.ufri.br
} 


\section{RevistAleph}

\section{Introdução}

A motivação da produção do artigo em questão surgiu através dos resultados positivos apesar de toda problemática do dificultoso processo pelo qual foi realizado o trabalho de avaliação e acompanhamento do percurso de um aluno surdo da UFRJ no Instituto de Química e por conta da observação de toda dificuldade de adaptação dos surdos ao ambiente universitário.

A dificuldade dos surdos na universidade inicia-se no acesso. Na aplicação das provas do ENEM. Esse processo já se mostra de uma complexidade peculiar. Isso se deve por conta do fato que a língua utilizada por esse público (no caso, a Libras - Língua Brasileira de Sinais) é diferente da corrente no nosso país (o Português). Apesar de os candidatos ao ingresso à universidade terem que dominar o Português escrito, não é de domínio completo do surdo que utiliza a primeira língua como a Libras e que os fazem se organizar cognitivamente. Hoje já se realiza a adaptação das provas e é permitida a presença de intérpretes de Libras através de videoconferência. Sendo que a Libras é uma língua de estrutura e forma completamente diferentes das outras línguas estrangeiras ou do português. Suas estruturas gramatical e sintática são diferenciadas e sua natureza semiótica é bimodal (viso-gestual), ou seja, um outro código linguístico. Não somente por isso, mas também pelo fato que se desdobra em outra problemática a ser enfrentada: os intérpretes que trabalham na interpretação por videoconferência serem de regiões diferentes dos candidatos e os sinais que são utilizados podem não ter significado igual para as regiões todas do país (QUADROS; KARNOPP, 2004).

Como se não bastasse o próprio exame do ENEM, quando o surdo chega à universidade para realizar seu processo de pré-matrícula e matrícula, a falta de profissionais nas secretarias de graduação com noções de Libras ou mesmo de intérpretes é outro grande enfrentamento. Na UFRJ, no processo da pré-matrícula, atualmente a DIRAC (Diretoria de Acessibilidade) dispõe de uma equipe de TILs (Técnicos em Interpretação de Libras) o que não ocorria na época de 2018, fato que 


\section{RevistAleph}

auxilia, mas não da forma como deveria, pois não são suficientes para a demanda de toda UFRJ.

Nos cursos de graduação na área de Letras-Libras na Faculdade de Letras há intérpretes para esse atendimento e orientações na matrícula dos seus cursos, porém os demais surdos de outras unidades acadêmicas como serão atendidos? Não há intérpretes suficientes.

Essa, inclusive é uma discussão constante no Fórum Permanente UFRJ Acessível e Inclusiva (FPAI) que nasceu da necessidade do tema da inclusão, processo a ser pensado, por causa da adoção das políticas afirmativas, chamadas de política de cotas, por conta da Lei 13.409, 2016 que é de âmbito Federal, a chamada "Lei das cotas" (BRASIL, 2016).

Uma vez matriculados, os surdos precisam se movimentar, transitar e permanecer na UFRJ. O campus que mais concentra alunos surdos da UFRJ é o da Cidade Universitária (justamente por abrigar o curso de Letras-Libras), conhecido como Ilha do Fundão. E tomando como exemplo o Fundão, observa-se que esse campus não é nada pequeno e que justamente tem a dimensão de uma pequena cidade. Por ele, o surdo terá que transitar em ônibus internos, tentar se comunicar nos refeitórios, cantinas, lojas, bancos que também não se adequam ao contexto da recepção de surdos.

Chegando à sala de aula, o aluno surdo encontra necessidade da presença de intérpretes principalmente nas salas de aulas e laboratórios. Fato que foi muito significativo na observação do aluno acompanhado pela autora.

O que ocorreu na realidade foi um conflito importante que a universidade encontrou em meio a força da "lei de cotas" $(L 13.409,2016)$ e a falta de estrutura e tempo hábil para uma possível adaptação a essa nova realidade e alunado com deficiência.

$\mathrm{Na}$ realidade, esse fato também ocorreu aliado à falta de investimento governamental na contratação de profissionais dessa área, gerando uma problemática 


\section{RevistAleph}

bastante séria que inviabilizaria o processo de aprendizagem e convivência no ambiente da universidade pelos surdos.

Tal fato foi discutido em plenárias do FPAl e em duas edições do evento chamado de ESUA (Encontro de Sensibilização UFRJ pela Acessibilidade), onde se pretendia reunir representantes de toda a comunidade universitária, autoridades e especialistas em um momento de troca de saberes e experiências, bem como propiciar um diálogo entre essa comunidade com os órgãos e setores internos a fim de que gerassem providências e ações.

As soluções momentâneas foram debatidas em plenárias, reuniões com as cúpulas e representações em câmaras de acordo com temas de trabalho, na UFRJ são 3: "projetos, obras, questões ambientais e qualidade de vida"; "assuntos acadêmicos" e "legislação". Essas soluções não foram geradas dessas instâncias que são de natureza deliberativa. A dimensão executiva ocorre no âmbito de cada unidade, pois cada unidade acadêmica possui autonomia, inclusive suas coordenações de cursos, colegiados e programas de pós-graduação.

Enquanto isso, no Instituto de Química (IQ-UFRJ), a direção quando contatada pela DIRAC, no início do ano de 2018, decidiu criar uma comissão que se responsabiliza, dentre outras atribuições da avaliação, pelo atendimento e orientação de docentes para trabalhar com pessoas com deficiência.

Assumiu-se conjuntamente, direção e a comissão criada, por conta da falta de recursos e limitações atuais, que as soluções para esse atendimento deveriam ser pensadas e elaboradas de forma a atender à demanda que chegava a cada semestre através de uma lista de alunos matriculados remetida pela DIRAC. As adaptações e soluções foram pensadas nas dimensões comunicacionais e atitudinais, pois seria o possível a curto e médio prazos. As barreiras arquitetônicas eram mais difíceis de execução de imediato, pois demandavam processos, projetos e investimentos que não eram somente da administração da direção de nossa unidade acadêmica.

O conjunto de soluções a nível institucional advindas da direção da unidade responsável pelo aluno surdo que cursaria disciplinas no IQ ocorreu de forma paliativa, 


\section{RevistAleph}

não definitiva. Foram oferecidas bolsas de auxílio de aprendizagem na área de Libras para alunos de graduação de Letras-Libras.

A DIRAC, por sua vez, solicitou geração de vagas e concursos para contratação de TILs ou a contratação por licitação de empresas que manteriam a universidade atendida através da formação de equipes de profissionais especializados desde a sua primeira gestão. Esse pedido foi remetido à reitoria através da pró-reitoria responsável por esses processos. Mas, foi declarado nas plenárias do FPAI que não havia como gerar vagas em concursos, e no caso das contratações, o processo de licitação é complicado e a longo prazo.

\section{Justificativa teórica}

O indivíduo surdo é diferenciado de outras pessoas com deficiência por utilizar uma forma diversificada de comunicação (SACKS, 1990). A forma de se comunicar através de sinais utiliza os modos gestual e visual, diferente do que o mundo dos ouvintes oralizados usam, ou seja, a língua falada (GOLDFELD, 1997; LACERDA, 2000; SACKS, 1990). Esse conflito é refletido em todo o processo de desenvolvimento cognitivo, portanto demandando uma escola que olhe para esse sujeito de outra forma, buscando equidade de acesso às informações necessárias para que ele aprenda (GOLDFELD, 1997; SACKS, 1990). Essa escola é conhecida como "inclusiva". Porém, historicamente o surdo tem se adaptado à escola bilíngue para surdos adotada em instituições “especiais” (GOLDFELD, 1997; LACERDA, 2000).

Esse processo não foi simples. Para isso, os surdos assumem perante à sociedade discursos de cunho mais político buscando por direitos e vencendo lutas que são traduzidas nas conquistas de alguns marcos legais apresentados no Quadro 1 (FRANCO, 2009). 


\section{RevistAleph}

Quadro 1 - Apresentação da cronologia dos principais marcos legais conquistados pelos surdos (1993-2016)

\begin{tabular}{|c|c|l|}
\hline Legislação & Ano & \multicolumn{1}{|c|}{ Conquista } \\
\hline PL4.066 & 1993 & $\begin{array}{l}\text { Começo da regulamentação e instituição da } \\
\text { Libras. }\end{array}$ \\
\hline L10.436 $^{1}$ & 2002 & $\begin{array}{l}\text { Oficializou a Libras como 2á língua oficial } \\
\text { brasileira. }\end{array}$ \\
\hline Decreto 5.626 $^{2}$ & 2005 & Libras como disciplina curricular. \\
\hline Desdobramento ${ }^{1} \mathrm{e}^{2}$ & 2007 & Aplicação da estrutura de língua para Libras. \\
\hline L12.319 $^{2}$ & 2016 & Regulamentação da profissão \\
\hline
\end{tabular}

Fonte: Própria autora.

O Quadro 1 apresenta a cronologia das conquistas alcançadas pelos surdos. Os marcos apresentados conversam entre si. Observa-se assim que o início dessa luta pela regulamentação e instituição da Língua Brasileira de Sinais (Libras) se dá em 1993 através do Projeto de Lei 4.066 e só se assinou uma Lei oficializando essa língua como a 2a língua oficial do Brasil em 2002. Tal fato desdobrou-se no Decreto 5.626 de 2002 que instituiu a disciplina de Libras como curricular e em 2007 aplicou-se a estrutura de língua para Libras. Desta maneira, regulamentou-se a profissão de tradutor/intérprete de Libras pela Lei 12.319, 2010.

Até a assinatura da Lei Brasileira da Inclusão (LBI), em 2015, no tocante à educação de surdos, baseava-se na Lei de Diretrizes e Bases da Educação (Lei 9.394, 


\section{RevistAleph}

1996). Em especial, dos artigos 58 ao 60 que contemplam o tópico da "Educação Especial".

A partir de 2015, a LBI, confere um caráter de inclusão com perspectiva especial à educação para pessoas com deficiência. Essa mudança de olhar tirou parte dos alunos com deficiência de escolas especiais (que ainda existem e têm papel fundamental no ensino pré-escolar e na alfabetização e em parte do Nível Fundamental I) levando-as às regulares. Assim, muitos dos seus direitos foram assegurados, porém muitos avanços legais dados para os surdos nesse aspecto parecem entrar em conflito, principalmente no que diz respeito à educação bilíngue para surdos (especializada) frente à educação regular (inclusiva). Essa problemática se acentua com o ingresso dos surdos ao Ensino Superior.

A possível divergência e enfrentamento pronunciados quando a Lei 13.409 de 2016 enuncia direito a vagas em universidades através de ações afirmativas para pessoas com deficiência (cotas) torna-se mais evidente. Essa questão é cada vez mais visível, pois agora o surdo se encontra no meio universitário que é preponderantemente oralizado.

A própria estrutura da universidade tem dificuldade em acolher este aluno, por exemplo: no caso do aluno que foi atendido entre 2018 e 2019 nas disciplinas de Bioquímica no IQ-UFRJ que ao não ser promovido de Bioquímica I para Bioquímica II teórica não conseguiu atendimento no turno em que foi oferecida, porém o docente responsável pela disciplina acatou às orientações emitidas pela comissão de acessibilidade, representada pela autora do artigo em questão e ao final do período letivo cursado o aluno conseguiu a aprovação, sendo avaliado muito positivamente conquistando nota da sua média sem necessidade de avaliação final.

Essa questão é importante, porém a população com alguma deficiência auditiva (dentre essas pessoas, os surdos) no Brasil representa apenas 5,2\% da população total brasileira, segundo o último Censo (IBGE, 2010). E segundo levantamento junto à DIRAC (Diretoria de Acessibilidade), tomando como exemplo a UFRJ, 120 alunos declaram-se pessoas com alguma deficiência auditiva com matrículas ativas nos cursos de Nível 


\section{RevistAleph}

Superior e Pós-Graduações, o que representa algo em torno de 0,2\% da UFRJ (total de alunos da UFRJ seria de 67.318, segundo "UFRJ em números" de 2013 - mais recente).

Por serem desenvolvidos em um ambiente, geralmente em escolas dedicadas à Educação Especial de surdos, esses educandos surdos ingressam na universidade em meio a um possível conflito apresentado entre a "escola bilíngue para surdos" e a "Educação Inclusiva” (FRANCO, 2009; SKLIAR, 1999).

Assim, grande dificuldade do discente surdo, principalmente o sinalizante usuário de Libras, sua L1 (primeira língua) ao ingressar (ter acesso) e permanecer na universidade pública, utilizando como exemplo dados de 2 períodos (2018-1 e 2018-2) e 1 período de 2019 (2019-1) - 1 ano - em que as políticas de ações afirmativas por deficiência foram aplicadas inicialmente na UFRJ, onde se pôde atender a um aluno no IQ-UFRJ.

\section{Metodologia}

Serão apresentados dados advindos da PR1-DRE/DIRAC-UFRJ de ingresso de alunos com deficiência auditiva e dos alunos surdos dos períodos de 2018-1 e 2018-2 matriculados na UFRJ e do aluno surdo nas disciplinas oferecidas em um determinado departamento do IQ-UFRJ até 2019-1. Tais disciplinas foram ministradas por docentes orientados pedagogicamente a adaptações curriculares e avaliativas pela comissão de acessibilidade, papel exercido hoje pela acessibilidade IQ (Direção-IQ-UFRJ), coordenado pela autora do artigo em questão. Frente a isso, serão relatadas experiências com discussões embasadas sob o ponto de vista legal, pedagógico e teórico. Serão ainda apresentados os consequentes desdobramentos, medidas e resultados conquistados pelo aluno surdo atendido e acompanhado pela autora no período de 2018-2019 no IQ-UFRJ.

\section{Resultados e discussão}




\section{RevistAleph}

Como resultados das políticas decorrentes da "lei cotas" (BRASIL, 2016) com respeito aos alunos surdos ingressantes na UFRJ, pode-se considerar que em 2018 foram matriculados na UFRJ surdos através da política de ações afirmativas por deficiência através do SiSU-ENEM nos seguintes cursos, como demonstrado através do Quadro 2:

Quadro 2 - Distribuição dos alunos surdos nos cursos de graduação na UFRJ em 2018

\begin{tabular}{|c|c|c|c|c|c|}
\hline Curso & Nível & Ingresso & Situação em 2020 & Deficiência & $\begin{array}{l}\text { Modalidade de } \\
\text { Ingresso }\end{array}$ \\
\hline \begin{tabular}{|l|} 
Licenciatura em \\
Letras - Libras \\
\end{tabular} & Graduação & 2018-1 & Ativa & Surdez & $\begin{array}{l}\text { Ampla } \\
\text { concorrência }\end{array}$ \\
\hline $\begin{array}{l}\text { Licenciatura em } \\
\text { Letras - Libras }\end{array}$ & Licenciatura & 2018-1 & $\begin{array}{l}\text { Matriculada com } \\
\text { Trancamento } \\
\text { Solicitado em } \\
\text { 2018-1. Sem CRID } \\
\text { em 2020-1 }\end{array}$ & Surdez & $\begin{array}{l}\text { Ampla } \\
\text { concorrência }\end{array}$ \\
\hline $\begin{array}{l}\text { Licenciatura em } \\
\text { Letras - Libras }\end{array}$ & Licenciatura & 2018-1 & Ativa & Surdez & $\begin{array}{l}\text { Ampla } \\
\text { concorrência }\end{array}$ \\
\hline $\begin{array}{l}\text { Licenciatura em } \\
\text { Letras - Libras }\end{array}$ & Licenciatura & 2018-1 & $\begin{array}{l}\text { Rematrícula por } \\
\text { destrancamento } \\
\text { ou } \\
\text { descancelamento. } \\
\text { Possui CRID em } \\
2020.1 \\
\end{array}$ & Surdez & $\begin{array}{l}\text { Ampla } \\
\text { concorrência }\end{array}$ \\
\hline \begin{tabular}{|l|} 
Licenciatura em \\
Letras - Libras \\
\end{tabular} & Licenciatura & 2018-1 & Ativa & Surdez & $\begin{array}{l}\text { Ampla } \\
\text { concorrência }\end{array}$ \\
\hline \begin{tabular}{|l|} 
Licenciatura em \\
Letras - Libras \\
\end{tabular} & Licenciatura & 2018-1 & Ativa & Surdez & $\begin{array}{l}\text { Ampla } \\
\text { concorrência }\end{array}$ \\
\hline \begin{tabular}{|l|} 
Licenciatura em \\
Letras - Libras
\end{tabular} & Licenciatura & 2018-1 & Ativa & Surdez & $\begin{array}{l}\text { Ampla } \\
\text { concorrência }\end{array}$ \\
\hline \begin{tabular}{|l|} 
Licenciatura em \\
Letras - Libras \\
\end{tabular} & graduação & 2018-1 & Ativa & Surdez & Deficiência \\
\hline \begin{tabular}{|l|} 
Licenciatura em \\
Letras - Libras \\
\end{tabular} & Licenciatura & 2018-1 & Ativa & Surdez & \begin{tabular}{|l|} 
Ampla \\
concorrência
\end{tabular} \\
\hline \begin{tabular}{|l|} 
Licenciatura em \\
Letras - Libras
\end{tabular} & Licenciatura & 2018-1 & Ativa & Surdez & $\begin{array}{l}\text { Ampla } \\
\text { concorrência }\end{array}$ \\
\hline Direito & Graduação & 2018-1 & Ativa & Surdez & $\begin{array}{l}\text { Escolar + Racial + } \\
\text { Deficiência } \\
\end{array}$ \\
\hline \begin{tabular}{|l|} 
Licenciatura em \\
Letras - Libras \\
\end{tabular} & Licenciatura & 2018-1 & Ativa & Surdez & $\begin{array}{l}\text { Ampla } \\
\text { concorrência }\end{array}$ \\
\hline $\begin{array}{l}\text { Licenciatura em } \\
\text { Educação } \\
\text { Artística - Artes } \\
\text { Plásticas } \\
\end{array}$ & Graduação & 2018-1 & Ativa & Surdez & $\begin{array}{l}\text { Escolar + Racial + } \\
\text { Deficiência }\end{array}$ \\
\hline
\end{tabular}




\section{RevistAleph}

\begin{tabular}{|c|c|c|c|c|c|}
\hline Medicina & Graduação & 2018-1 & Ativa & Surdez & $\begin{array}{l}\text { Escolar + Renda + } \\
\text { Racial + Deficiência }\end{array}$ \\
\hline $\begin{array}{l}\text { Licenciatura em } \\
\text { Letras - Libras }\end{array}$ & Graduação & 2018-1 & $\begin{array}{l}\text { Ativa. Sem CRID } \\
\text { em 2020-1 }\end{array}$ & Surdez & $\begin{array}{l}\text { Ampla } \\
\text { concorrência }\end{array}$ \\
\hline $\begin{array}{l}\text { Licenciatura em } \\
\text { Letras - Libras }\end{array}$ & Licenciatura & 2018-1 & Ativa & Surdez & $\begin{array}{l}\text { Ampla } \\
\text { concorrência }\end{array}$ \\
\hline $\begin{array}{l}\text { Licenciatura em } \\
\text { Letras - Libras }\end{array}$ & Licenciatura & 2018-1 & $\begin{array}{l}\text { Matrícula com } \\
\text { Trancamento } \\
\text { Solicitado em } \\
\text { 2019-1 }\end{array}$ & Surdez & $\begin{array}{l}\text { Ampla } \\
\text { concorrência }\end{array}$ \\
\hline $\begin{array}{l}\text { Bacharelado em } \\
\text { Letras - Libras }\end{array}$ & Bacharelado & 2018-1 & Ativa & Surdez & $\begin{array}{l}\text { Ampla } \\
\text { concorrência }\end{array}$ \\
\hline $\begin{array}{l}\text { Licenciatura em } \\
\text { Química - EAD } \\
\text { (CEDERJ) }\end{array}$ & Graduação & 2018-1 & $\begin{array}{l}\text { sem informação. } \\
\text { Não cursou 2019- } \\
2\end{array}$ & Surdez & $\begin{array}{l}\text { Ampla } \\
\text { Concorrência }\end{array}$ \\
\hline $\begin{array}{l}\text { Licenciatura em } \\
\text { Letras - Libras }\end{array}$ & Graduação & 2018-1 & Ativa & Surdez & $\begin{array}{l}\text { Ampla } \\
\text { concorrência }\end{array}$ \\
\hline Fonoaudiologia & Graduação & 2018-1 & Ativa & Surdez & $\begin{array}{l}\text { Escolar + } \\
\text { Deficiência }\end{array}$ \\
\hline $\begin{array}{l}\text { Licenciatura em } \\
\text { Letras - Libras }\end{array}$ & Graduação & 2018-1 & $\begin{array}{l}\text { Abandono em } \\
\text { 2019-2 }\end{array}$ & Surdez & $\begin{array}{l}\text { Ampla } \\
\text { concorrência }\end{array}$ \\
\hline
\end{tabular}

Fonte: PR1/DRE e DIRAC - UFRJ.

Percebe-se que, muitos surdos, especificamente falando de 16 dos 21 alunos no total ingressaram em Letras-Libras da Faculdade de Letras da UFRJ, o que significa dizer que um pouco mais de $76 \%$ dos alunos surdos vão para a área de Letras-Libras, entre os cursos de Licenciatura e Bacharelado. O que parece ser natural, pois trata-se da área que oferece recursos para os discentes, tais como os intérpretes de Libras para assistirem às aulas em seu curso de graduação.

Já os outros poucos observados estão distribuídos por cursos diversos: (1) Direito; (1) Educação Artística - Artes Plásticas; (1) Medicina; (1) Licenciatura em Química (Modalidade EaD (Ensino à Distância), sob atendimento e responsabilidade do núcleo pedagógico criado pela Fundação CECIERJ/CEDERJ); (1) Fonoaudiologia, ou seja, aproximadamente $5 \%$ dos alunos Surdos para cada curso.

Acredita-se que a ausência de surdos ingressantes no período de 2018-2 possa ter sido devido à mudança de critério de ingresso de pessoas com deficiência pelas políticas de ações afirmativas por deficiência nos cursos de graduação na UFRJ. Essa questão foi bastante debatida no Fórum UFRJ Permanente e Inclusivo (FPAI-UFRJ). 


\section{RevistAleph}

Quanto ao aluno atendido pela comissão de acessibilidade que foi matriculado no período anterior, em 2017-2, será considerado como o objeto do estudo da autora por ter sido o único aluno que cursou disciplinas de responsabilidade da comissão anteriormente citada do IQ.

Tal experiência foi muito rica e trouxe imensos aprendizados para a comissão de acessibilidade e para os docentes envolvidos no período de 2018-2019. Várias reuniões de planejamento foram realizadas antes da chegada do aluno. Isso levou a equipe a pensar em materiais adaptados e em qual forma de se comunicar ao trabalhar com o aluno.

Outro ponto considerado seria o de como ministrar as aulas de laboratório e teóricas na presença de alunos bolsistas intérpretes. Esse diálogo foi determinante para estabelecer uma parceria presente da comissão de acessibilidade com os professores e técnicos que iriam trabalhar pedagogicamente com o aluno.

O aluno citado chegou ao departamento para assistir às aulas teóricas e práticas no período de 2018-1. Logo, com isso, veio a ser atendido por nossa comissão de acessibilidade. A autora foi a responsável pelo acolhimento do aluno para uma avaliação funcional com a finalidade da elaboração de um documento de orientação pedagógica para os docentes da equipe da disciplina.

Nesse documento, sugeria-se o uso de alguns recursos específicos acessíveis. As tecnologias assistivas de computador e celular foram sugeridas. Além disso, foi aconselhado para os docentes envolvidos medidas tais como, por exemplo: envio por $e$ mail do material de aula antecipado em arquivos em formato PDF (lidos em aplicativos de celular ou programas leitores de PDF em notebook ou microcomputador).

Se o aluno não dispusesse dos recursos próprios, oferecer o material impresso para acompanhar as aulas, permitir o uso do celular para comunicação entre aluno e professor, monitores e técnica de laboratório.

Orientou-se a presença de intérpretes de Libras nas aulas. Mencionou-se o uso de gravação de aulas para transcrição por aplicativos que exercem tal função, pois no caso desse aluno, em específico, não adiantaria muito que o professor ficasse à sua frente para leitura labial. Ele não declarava a prática dessa técnica. 


\section{RevistAleph}

Aconselhou-se realização de algumas adaptações curriculares e avaliativas, indicando-se que o tempo de execução de avaliações fosse mais prolongado e que ele pudesse usar o seu material teórico para consulta.

O diálogo com os professores foi constante.

Foram oferecidos bolsistas de auxílio de aprendizagem na área de Libras provenientes de períodos finais do curso de Letras-Libras da Faculdade de Letras da UFRJ.

Ainda se orientou que o aluno estudasse por livros textos que foram fornecidos em formato de PDF para auxiliá-lo.

Nem todas as medidas foram aprovadas e executadas, mas a maioria das medidas tomadas pela equipe foram mediadas pela comissão de acessibilidade e com o próprio aluno na presença das bolsistas intérpretes ou com o uso de aplicativo entre o professor e o aluno mais diretamente.

Nessa primeira disciplina, apesar da grande dificuldade, das faltas e atrasos das intérpretes, do próprio aluno e das suas dispersões naturais - o processo de assistir aula em português para o surdo é bastante cansativo, pois ao acompanhar as aulas em Libras e não ter um escriba para registrar as anotações o dividia. Além do cansaço já denunciado por acordar muito cedo, morar longe da universidade, da condução cheia e pouco confortável, esse conjunto de fatos o levava a se sentir cansado ao chegar na aula e isso culminava em muitos momentos de desligamento completo de todo contexto. Apesar de todo esse cenário, as suas dificuldades foram ultrapassadas até a conquista de sua aprovação.

Porém na disciplina posterior, no período de 2018-2, infelizmente, apesar de já ambientado e utilizando os mesmos recursos e os professores também já bem orientados, o aluno não obteve o mesmo resultado na parte teórica. Mesmo com desempenho bom e satisfatório em laboratório para que fosse liberado, o discente não conseguiu nota nem mediana para sua aprovação, mesmo com a presença de bolsistas intérpretes.

É importante destacar que a equipe pensou em disponibilizar um monitor de pós-graduação para atendê-lo, além da presença das alunas bolsistas intérpretes. 


\section{RevistAleph}

Sua reprovação impactou em seu horário no período seguinte, pois em 20191, por conta de outros compromissos de seu curso, só conseguiu se matricular na disciplina no turno da noite.

Isso causou uma questão séria: os bolsistas faziam licenciatura em Letras-Libras no mesmo turno em que ele faria a disciplina, assim não haveria como atendê-lo. Esse fato levou o aluno a realizar a disciplina à noite sem presença de alunos bolsistas intérpretes.

Com esse fato, a equipe docente decidiu dispensar o aluno da parte prática da disciplina, pois sua nota no período anterior o permitiria que isso fosse concedido. Assim, o discente cursou a disciplina somente teórica com um reforço na orientação ao docente regente da turma.

No decorrer do curso todo, pouco o professor se comunicou, porém sempre que a autora o encontrava interpelava como estava o percurso das aulas com o aluno e ele inicialmente relatou a dificuldade e algumas notas baixas, porém o esforço para sempre o manter com o material escrito e a atenção desdobrada eram nítidos.

Da metade até o final do período o professor relatou alguma evolução para melhora da situação anterior, tanto do interesse quanto comunicação demonstrando bem mais esforço do discente.

Particularmente o aluno demonstrava muita vontade de superar tais problemas e por isso, acreditava-se na sua aprovação.

Ao final do período o aluno se comunicou, relatando a aprovação sem necessidade de prova final sequer. Quando encontrado, o docente relatou que o esforço foi mérito do aluno, pois ele teria passado com nota acima da média.

Vale ressaltar que o aluno em meio a 3 períodos e 2 disciplinas realizadas ainda ao interagir com a equipe departamental participou junto à equipe de bolsistas intérpretes de atividades de extensão na Semana Nacional de Ciência e Tecnologia (SNCT- UFRJ -2018) desenvolvendo um vídeo em Libras para anunciar uma atividade acessível. 


\section{RevistAleph}

Nessa atividade, ele relatou que o sentimento de pertencimento ao ambiente do IQ-UFRJ foi maior e que ele se dispunha a participar de outras atividades dessa natureza.

O aluno também foi convidado a conversar e frequentar as palestras da disciplina de seminários que é um projeto dentro da temática dos surdos no centro ao qual seu curso pertence e que se desenvolveu dentro desse período. $\mathrm{O}$ aluno aceitou e compareceu a uma palestra em que estavam alunos surdos também de outros campi da UFRJ e mostrou muito interesse no que foi dito.

Ele ainda visitou o laboratório onde à coordenadora desse projeto é pesquisadora e em conversa com ela e com a técnica onde se realizam atividades com surdos foi bastante proveitosa e frutífera, pois lá ele demonstrou também uma espécie de sentimento de acolhimento (segundo seus relatos posteriores e reações em contato com as duas especialistas).

É importante ainda salientar que o aluno tratado no artigo em questão escreve e lê bem português, pois frequentou escola regular por toda sua vida escolar na Educação Básica. Ele declarou que seu ensino não foi especial, além disso sua L1 (língua de alfabetização) foi o Português, aprendendo depois Libras como L2, sua segunda língua.

A partir daí, preferencialmente se comunica e se organiza mental e cognitivamente por sinais, o que confere a ele características diferenciadas frente aos demais alunos conhecidos que a L1 é a Libras.

Por ter vindo de escolas regulares e costumeiramente ser incluído em classes regulares durante o seu percurso escolar no Ensino Básico, ele apresenta uma característica que o auxilia na inclusão nos ambientes da UFRJ: é muito social.

O aluno mostra-se bastante interativo com os seus colegas. Essa aproximação e interação o beneficia no sentido que seus colegas auxiliam bastante em suas disciplinas. 


\section{RevistAleph}

\section{Considerações finais}

É notável que existam problemas infra estruturais na recepção e permanência de alunos surdos na UFRJ. Isso é uma questão presente em outras universidades públicas e também no Ensino Básico.

A problemática de uma língua diferente do português, como é a Libras, com uma estrutura e gramática diferenciadas do idioma predominante dentre os discentes, apresenta uma nova realidade, onde é preciso respeitar a diversidade linguística bem como cultural dessa comunidade.

Os surdos possuem outra forma de comunicação entre si e com os ouvintes. Para isso, é necessário em caráter urgente a geração de vagas ou contrato de empresas que tragam para o ambiente da UFRJ os profissionais/técnicos qualificados para o trabalho com os alunos que necessitam da interpretação em Libras. Tal medida é importante para a compreensão do que é falado em sala de aula pelos docentes que ministram as disciplinas em que esses alunos terão de ser matriculados em seus cursos de graduação.

Importantíssimo que a reitoria e DIRAC, bem como as unidades acadêmicas se dediquem à formação específica dos alunos bolsistas de auxílio de aprendizagem para atuarem em áreas como Biologia, Química, Física, Matemática e tantas outras, pois nem sempre esses alunos intérpretes conhecem e dominam os vocabulários específicos em Libras das áreas específicas.

No caso de disciplinas laboratoriais, é importante o estímulo de capacitação e disponibilidade de um monitor, preferencialmente de pós-graduação que atue na disciplina em que essa atividade prática. Tal medida foi determinante no processo de aprendizagem do aluno estudado, pois a ele foi disponibilizado um monitor altamente qualificado, aluno de doutorado, com graduado na mesma área do curso que o aluno e que ficou à disposição inteiramente dele enquanto realizava atividades práticas de laboratório, além das bolsistas intérpretes que compareciam a essas práticas.

Para melhor desempenho dos alunos surdos, seria interessante 0 desenvolvimento de acervo em vídeo em Libras utilizando a tecnologia de $Q R$ Code. Esse 


\section{RevistAleph}

trabalho deve ser desenvolvido pelas equipes dos departamentos que oferecem disciplinas para tais alunos e a equipe de TILs e bolsistas que estejam disponíveis para tal atividade. Essa necessidade aliada à boa vontade dos envolvidos pode vir a realizar acervos bem interessantes para uso geral dos próximos alunos surdos que viessem a porventura cursar as disciplinas citadas, porém para realização desse feito é necessário que se disponibilizem os recursos tais como estúdios, aparelhos de gravação de vídeo, profissionais experientes em edição de vídeos com janelas de Libras.

O desenvolvimento do aluno pode também ser promovido e estimulado com auxílio de tecnologias assistivas, portanto, seria interessante capacitar os professores, monitores, técnicos, bibliotecários e quem viesse a ter contato com os alunos surdos para melhor utilização do mínimo de aplicativos em plataformas de celular para comunicação em Libras ou troca de textos instantâneos para que possam saber o que esse público surdo necessita e deseja nos ambientes da UFRJ.

O uso de material em texto, com imagens e utilizando $Q R$ Code pode beneficiar a comunicação e o aprendizado desse público-alvo. Os surdos conseguem ser incluídos com mais autonomia quando tais recursos são disponibilizados para eles.

Sinalizações e atendentes com noções de Libras ou munidas de aparelhos com aplicativos que possam viabilizar uma comunicação mínima em texto ou Libras podem ajudar muito na convivência e mobilização dos surdos por todos os espaços necessários dentro da universidade.

Por fim, lembrando que nem todos os recursos e barreiras demandam somente investimento financeiro alto. Muito do que é necessário para inclusão de surdos bem como de outras pessoas com deficiência são de ordem comunicacional e atitudinal, bastando a sensibilização e algumas adaptações razoáveis utilizando bom senso e postura mais empática por parte da comunidade universitária ouvinte como um todo. 


\section{RevistAleph}

\section{Referências}

BRASIL. Decreto 5.626, de 22 de dezembro de 2005. Disponível em:

http://www2.camara.leg.br/legin/fed/decret/2005/decreto-5626-22-dezembro-2005-539842publicacaooriginal-39399-pe.html, acesso em: 01/2019.

BRASIL. Lei 9.394, de 20 de dezembro de 1996 - Lei de Diretrizes e Bases da Educação (LDB). Disponível em: http://www.planalto.gov.br/ccivil_03/LEIS/L9394.htm, acesso em: 01/2019.

BRASIL. Lei 10.436, de 24 de abril de 2002 - Lei da Libras. Disponível em: http://www.planalto.gov.br/ccivil_03/LEIS/2002/L10436.htm, acesso em:01/2019.

BRASIL. Lei 12.319, de 10 de setembro de 2010. Regulamenta profissão de tradutor/intérprete de Libras. Disponível em: http://www.planalto.gov.br/ccivil_03/_ato2007-

2010/2010/lei//12319.htm, acesso em: 01/2019.

BRASIL. Lei 13.146, de 6 de julho de 2015 - Lei Brasileira da Inclusão (LBI). Disponível em: http://www.planalto.gov.br/CCIVIL_03/_Ato2015-2018/2015/Lei/L13146.htm, acesso em: 01/2019.

BRASIL. Lei 13.409, de 28 de dezembro de 2016 - sobre a reserva de vagas para pessoas com deficiência nos cursos técnico de nível médio e superior das instituições federais de ensino (Lei das Cotas). Disponível em: http://www2.camara.leg.br/legin/fed/lei/2016/lei-13409-28dezembro-2016-784149-publicacaooriginal-151756-pl.html, acesso em: 01/2019.

BRASIL. PL 4.066, de 1993. Disponível em:

http://www.camara.gov.br/proposicoesWeb/fichadetramitacao?idProposicao=218472, acesso em: 01/2019.

FRANCO M. Educação Superior Bilíngue para surdos: o sentido da Política Inclusiva como espaço da liberdade: primeiras aproximações. Rev. Bras. Ed. Esp., Marília, v.15, n.1, p.15-30, jan.-abr. 2009.

GOLDFELD M. A criança surda: linguagem e cognição numa perspectiva sociointeracionista. São Paulo: Plexus, 1997. 176 p.

IBGE - Instituto Brasileiro de Geografia e Estatística - Censo 2010. Disponível em: https://censo2010.ibge.gov.br/, acesso em: 01/2019.

LACERDA, C. B. F. de. A prática pedagógica mediada (também) pela língua de sinais: trabalhando com sujeitos surdos. Cadernos Cedes, ano XX, n. 50, abril/2000, p. 70 - 83.

QUADROS, R. M. KARNOPP, L. B. Língua de Sinais Brasileira: estudos linguísticos. Porto Alegre: Artmed, 2004.

SACKS, O. Vendo Vozes: Uma jornada pelo mundo dos surdos. Rio de Janeiro: Imago Editora, 1990. 


\section{RevistAleph}

SKLIAR, C. A. Educação para os surdos: entre a pedagogia especial e as políticas para as diferenças. In: Seminário Desafios e Possibilidades na Educação Bilíngüe para surdos, 1997, Rio de Janeiro. Anais. Rio de Janeiro: INES, 1997. p.32- 47.

UFRJ em Números. Rio de Janeiro: UFRJ, 2013. Disponível em: https://ufrj.br/docs/lai/ufrj-emnumeros-2013.pdf, acesso em: 01/2019.

Data do envio: $14 / 09 / 2020$.

Data do aceite: $02 / 12 / 2020$. 